\title{
A Cross-cultural Study of Pragmatic Identities Constructed in Chinese and American Marketing Discourse on Social Media
}

\author{
Yue Siwei \\ School of English for International Business, Guangdong University of Foreign Studies, Guangzhou, China \\ Email address: \\ yue111_2000@126.com

\section{To cite this article:} \\ Yue Siwei. A Cross-cultural Study of Pragmatic Identities Constructed in Chinese and American Marketing Discourse on Social Media. \\ International Journal of Literature and Arts. Vol. 8, No. 3, 2020, pp. 153-161. doi: 10.11648/j.ijla.20200803.18
}

Received: February 27, 2020; Accepted: March 10, 2020; Published: April 23, 2020

\begin{abstract}
Based on a mini-corpus of Chinese and American marketing discourse on social media (150 discourses each), this study conducts a cross-cultural investigation of pragmatic identity construction in marketing discourse on social media. The results show that in the context of social media, a larger variety of individual pragmatic identities rather than organizational pragmatic identities is employed in both American and Chinese marketing discourses. Chinese and American enterprises both construct six different types of individual pragmatic identities (Experiencer, Sales Representative, Friend, Adviser, Expert and Official Introducer) in marketing discourse. Both Chinese and American marketing discourses tend to build official introducer and sales representative identity more than other identities. Adviser identity is not regularly constructed in both Chinese and American discourses. American marketing discourse on social media adopts the identity of experiencer and adviser more whereas Chinese discourse adopts expert and official introducer identity more than its counterpart. American discourse adopts more subjective identities than objective identities whereas Chinese discourse evenly employs both subjective and objective identities. Three cultural value dimensions (collectivism vs. individualism, high power distance vs. low power distance, relation-driven vs. task-driven) attribute to the different use of the pragmatic identities.
\end{abstract}

Keywords: Pragmatic Identity, Marketing Discourse, Social Media, Cross-cultural Study, Cultural Value Dimensions

\section{Introduction}

China has the world's most active social media environment: more than 300 million people use some form of social media including blogging and social-networking sites, and the average Chinese online user spends more than 40 percent of online time on social media [1]. Social media have become an important part of the consumer experience in China. For instance, WeChat, the dominating social media app in China, has been embraced as an important platform to conduct e-commerce where marketing strategies are deployed and executed through the dissemination of marketing discourse on "sharing the moment" and "public account". Not only businesses in China, but all companies and organizations in every corner of the world endeavor to keep pace with their digital savvy public in the midst of the social media boom by launching, disseminating marketing discourse on social media $[2,3]$. Not solely relying on the organizational identity, marketers on social media construct more diversified pragmatic identities which are created, negotiated in the process of communication, influenced by communicative purpose and context [4]. Unlike the conventional conception of social identity which is established or stereotyped prior to communicative practice, pragmatic identity is a flexible, dynamic, temporary and diversified social identity created and negotiated in the process of communication, influenced by communicative purpose and context [5-7]. According to pragmatic identity theory, one marketer on social media could tactically choose from multiple social identities a particular one at a time to serve different communicative purposes in the dynamic social media context. The choice of the pragmatic identity and its construction is by nature a pragmatic process which has an impact on how effectively a particular marketing strategy is implemented to establish a dynamic relationship with the customers or the public who regularly use social media. 
This research conducts a cross-cultural study of pragmatic identity constructed in Chinese and American marketing discourse on social media, aiming to uncover the similarities and differences of their characteristics and cultural roots.

To achieve this research objective, three research questions are proposed as follows:

1. What pragmatic identities do Chinese and American enterprises construct respectively in marketing discourse on social media?

2. What are the similarities and differences of pragmatic identities constructed in Chinese and American marketing discourse on social media? And why?

3. What strategies of pragmatic identity construction can be implemented by Chinese and American enterprises which intend to enter their counterpart's market?

\section{Literature Review}

\subsection{Pragmatic Identity and Marketing Discourse on Social Media}

According to Chen, pragmatic identity is the actual embodiment, application or construction of a particular social identity in communication. Identity is a pragmatic resource that can be invoked and utilized by communicators to adapt to the contextual factors so as to achieve particular communicative goals [5]. Different from conventional conception of fixed and static social identity, based on adaptation theory, pragmatic identity perceives identity of communicators as a flexible, dynamic, temporary and diversified social identity created and negotiated in the process of interaction, determined by communicative purpose and context $[5,7]$.

The dynamic and negotiable features of pragmatic identity have drawn an increasing attention from linguistic scholars. Some studies examined the pragmatic identity construction of master's and doctoral dissertation and found some drawbacks of the construction of pragmatic identity in the dissertation [8, 9]. However, some pragmatic identities discussed in these studies are not well defined, causing some confusion about the interpretation of the concept. A more clear-cut definition and classification of various pragmatic identities are in urgent need, along with a more explicit delineation of the linguistic manifestation. Some other studies concentrated on pragmatic identities constructed in a particular setting such as pragmatic identities constructed by English teachers during in-class teaching activities [10, 11], pragmatic identities of government officials [12], how pragmatic identities are realized in translation [13] or business communication [7], etc. Despite considerable attention given to the study of pragmatic identity, few works focus on the pragmatic identity constructed and utilized in marketing discourse, not to mention marketing discourse on an emerging medium of marketing--social media.

In the study of how an identity is constructed by a communicator, Tracy pointed out that discourse communication is discursive practice in essence and that a communicator constructs his or her pragmatic identity by simple means of personal instruction practice, verbal behavior, the voice, the choice of the language, and by complicated means of interaction structure, direct degree, narrating and position marking [14]. Chen agreed with Tracy and further classified discursive practice into choice of code and style, text characteristic, contents, verbal pattern, verbal behavior, address form, choice of grammar, choice of vocabulary, voice characteristic, and non-verbal characteristic. The finding offers us a systematic basis to analyze discourses and build pragmatic identities on them. When constructing a pragmatic identity, communicators choose it according to their communication demands, according to Chen, to meet specific communication demands [5]. Following Chen's study, Yuan described an analytical framework to depict the dynamic adaptive process of pragmatic identity in the communication, which is reflected in variability, negotiability, and functionality of pragmatic identity, followed by strategies of pragmatic identity construction in marketing discourse for SMEs (Small and Medium-sized Enterprises) [7].

This study discusses the cultural similarities and differences in pragmatic identity constructed in Chinese and American marketing discourse on social media, aiming to give some pragmatic strategies for both Chinese and American SMEs which are expanding overseas markets.

Marketing discourse on social media, in this research, is defined as the discourse written by the enterprises or their agents to achieve the direct or indirect marketing purposes, disseminated through social media platform.

Marketing discourse on social media employs diverse pragmatic identities to establish a dynamic relationship with the customers or the public who regularly use social media. Marketers on social media have multiple social identities prior to communication. However, they choose from them a particular one at a time to enact a particular utterance in the dynamic context, which is by nature a pragmatic process. What type of the pragmatic identity is chosen and how it is constructed by the communicator has an impact on how effectively a particular marketing strategy is implemented on social media.

This research undertakes a cross-cultural study of pragmatic identity constructed in Chinese and American Marketing Discourse on Social Media.

\subsection{Pragmatic Identity and Its Discursive Representation}

Identity is a pragmatic resource that can be invoked and utilized by communicators to adapt to the contextual factors so as to achieve particular communicative goals [5]. The dynamic online identity used by the communicator in communication is pragmatic identity, and the speaker's identity is used as a part of the pragmatic resources to promote the realization of the communicative purpose. This includes two levels of meaning: First, the pragmatic identity is the pragmatics of the social identity of the communicator, which is regarded as a part of the pragmatic resources and potential context by the communicator. Secondly, since communicators do not simultaneously construct multiple 
identities in a particular process of conversation, dynamic online identities used in current communication constitute pragmatic identities. Chen proposed that a communicator constructs his pragmatic identity by 11 types of linguistic representation, namely, linguistic code, style, discourse, content, speech mode, speech act, address form, grammar, vocabulary, phonology and paralanguage [5].

\section{Methodology}

\subsection{Research Design}

This research employs both qualitative and quantitative methods to conduct a comparative study of pragmatic identity constructed in Chinese and American marketing discourse on social media. Qualitative research is particularly appropriate for theory building because it allows the researcher to identify the themes and patterns that emerge from thick description, provides a source of new hypotheses and constructs, and generates theoretical explanation closely grounded in the event being observed [15]. Therefore, for the first stage, a qualitative analysis is carried out based on the observation of data and case studies to recognize and define different pragmatic identities constructed in Chinese and American marketing discourse. An exhaustive set of classified pragmatic identities are sorted out for the follow-up extensive analysis.

The second stage is a quantitative analysis of the distribution of all kinds of pragmatic identities constructed in Chinese and American marketing discourse on social media. One Chinese mini-corpus of marketing discourse on social media and its American counterpart are built for the quantitative study. Comparative study method is also adopted at this stage to detect the similarities and differences of pragmatic identities constructed in Chinese and American marketing discourse on social media. At this stage, our study obtains a holistic picture of how and why marketers from different cultural backgrounds display unique features of pragmatic identity construction in the marketing discourse on social media.

At the last stage, according to the major findings of previous comparative investigation, this research proposes formative strategies for Chinese and American enterprises to construct proper pragmatic identities tailoring to target overseas market.

\subsection{Data Collection}

Our primary source of data for this study consists of one Chinese mini-corpus of marketing discourse from Chinese mainstream social media platforms- Sina Weibo, WeChat-Share the moment, Wechat-public account, and its American counterpart from American mainstream social media platforms-Facebook and Twitter. Based on convenient sampling method, this study selects 5 types of products, namely, sportswear, hi-tech product, beverage, fast food and home appliances to collect marketing discourse. For each type of product, one prestigious Chinese brand and its American counterpart are paired for follow-up comparative studies (See Table 1).
Table 1. Profile of Chinese and American Brands for Pragmatic Identity Examination.

\begin{tabular}{lll}
\hline Product Type & Chinese Brand Name & American Brand Name \\
\hline Sportswear & Li Ning & Nike \\
Hi-tech Product & HUAWEI & Apple \\
Beverage & JDB & Coca Cola \\
Fast Food & Zhen Kungfu & Burger King \\
Home Appliance & GREE & Whirlpool \\
\hline
\end{tabular}

Posted on its official social media account, each brand's 30 discourse (in total 300 discourse) collected from 7, Jan. 2018 to 12 , September, 2018 are examined for this research.

\subsection{Data Analysis}

Based on Chen's proposal of 11 types of linguistic representation of identity construction [5], we firstly recognized the pragmatic identity types in Chinese and American marketing discourse on social media respectively by examining the marketing discourse. Secondly, we marked 300 pieces of discourse with the pragmatic identities detected in the first stage, and then calculated the frequency of each pragmatic identity type separately constructed by Chinese and American enterprises. By analyzing the proportion of each pragmatic identity, we can know what kind of pragmatic identity the two countries tend to construct.

Lastly, different from previous studies of pragmatic identity construction in various genres which discuss its characteristics simply from the linguistic perspective, this study assumed the reasons for the contrastive results rooted in its cultural divides. We attempted to approach pragmatic identity features in terms of national culture. Finally, some suggestions are drawn from the data analysis for Chinese and American SMEs to adapt to its counterpart's local market.

\section{Results}

\subsection{Types of Pragmatic Identity Constructed in Marketing Discourse on Social Media}

Manifested by address term, content, context and style with reference to Chen's model of linguistic representation of pragmatic identity [5], the marketing discourse constructs the following six pragmatic identities, which can be classified into emotional identity and rational identity. Subjective identity is constructed with sentimental words to trigger resonance of the consumers, while objective identity is constructed with logical and objective words that just provide information rather than apparently persuade consumers to buy the products.

Table 2. Types of Pragmatic Identity Constructed in the Marketing Discourse.

\begin{tabular}{ll}
\hline & experiencer \\
subjective identity & friend \\
& sales representative \\
& adviser \\
objective identity & expert \\
& official introducer \\
\hline
\end{tabular}

As is shown in Table 2, subjective identity entails identity of experiencer, friend, sales representative and advisor. 
Objective identity includes identity of expert and official introducer. Each pragmatic identity has different features and is constructed to achieve certain communicative purposes, which will be delineated below.

\subsubsection{Experiencer}

The pragmatic identity of experiencer refers to a user who benefits from the product and its added value and shares his feelings and sentiments with customers or the public. The following two examples of marketing discourse on American and Chinese social media both construct the pragmatic identity of experiencer.

Extract 1

I only love my fries and my whopper. I'm sorry. Heaven is a place called "pie made with Twix."

In this American marketing discourse on Twitter, instead of being a marketer, the discourse constructs an identity of experiencer who shares with the customers or the public the feeling of being in the heaven when he's enjoying fries and whopper.

Similarly, here is another construction of experiencer identity in one Chinese marketing discourse on SinaWeibo.

Extract 2

仙鹤与飞天图案的中国李宁帽衫作品，呈现于纽约时 装周舞台，为秀场增添了中国韵味之美李宁于苏绣的结 合，让我们再次领略了中国传统艺术之奥妙。

Translated text: The works of Chinese Li Ning hoodies with crane and flying sky patterns are presented on the stage of New York Fashion Week, which adds the beauty of Chinese charm to the show. The combination of Li Ning and Su Embroidery makes us appreciate the mystery of Chinese traditional art once again.

The discourse uses "on the stage" to create a fashion show scenery and the pronoun "us" to engage the author in the fashion show as a front row audience. The experiencer on spot of a fashion show shares the mysterious feeling with the public.

The establishment of experiencer identity in marketing discourse aims to engage the reader of the discourse in the scenario which activates all senses of the reader as if he is experiencing what the marketer is experiencing. Therefore, the empathy is generated between the marketer and the reader who is supposed to be the potential customer.

\subsubsection{Friend}

The pragmatic identity of friend denotes a peer who attempts to develop friendship with consumers and maintains a personal relationship with them. See this example of American marketing discourse on Twitter.

Extract 3

Did you know today is national send a card to a friend day? we didn't either if only we could send something a little more delicious than the fries we share.

In this example, the pronoun "we" makes the marketer and the consumer more connected. The key word "friend" here sets a frame, in which the marketer's selling delicious fries becomes a gift-giving act done by a friend. Accordingly, a closer relationship has been established with its customers.
Again the identity of friend is built up in this Chinese marketing discourse on Weibo.

\section{Extract 4}

各位宝宝们别忘了喝点暖身弹!

Translated Text: My babes, don't forget to have some warm porridge!

The address form "My babes" manifests an intimate relationship which is considered a unconventional relationship between enterprises and their customers. This unusual misplacement of address form is deliberately deployed to create the enterprise's pragmatic identity of a close friend who is obliged to extend care and love to you.

Creating a pragmatic identity of friend in communicating with customers is a prominent discursive strategy in marketing on social media. The identity of friend help the marketer gain credibility from the customer. Social media's unique feature of interactivity and informality enables the creation of the identity of friend mainly through the language style and the appropriation of intimate address form and particular pronoun.

\subsubsection{Sales Representative}

The pragmatic identity of sales representative is a seller who conveys the information of the product, brand or service to the user so as to make people aware of its existence, become attracted to it and finally purchase it in preference over others.

Extract 5

If the whopper has taught us anything, it's that some things are better flame grilled. ... You need those. The key to success is believing in yourself. Especially when you want a Whopper.

The speech act of promoting is realized through an evaluative adjective "better" and verbs "need" and "want". These words carry the intention of generating customers" needs and wants, and persuading the public to purchase, which constructs the pragmatic identity of sales representative. This strategy can also be found in Chinese marketing discourse on Weibo.

\section{Extract 6}

酸双无比的酸豆角肉沫饭，来了！！入口酸双可口，鲜 辣味美, 让你食欲大增, 又开胃，而且听说现在还有限时 优惠哟! 快到门店去看看吧!

Translated text: Here comes sour and refreshing minced pork rice with sour beans!! The sour, crispy and spicy taste will greatly increase your appetite. It's said a count-down sales campaign is in progress. Go to the store right now!

The modifier "sour" "refreshing","crispy" and "spicy" depicts the taste of the delicacy. The mentioning of count-down sales campaign provides the favorable information concerning pricing strategy. The fast-food chain restaurant performs the identity of a sales representative in this marketing discourse by describing the features of the products (taste) and informing the promotion activity. Besides, the exclamative sentence "Here comes..." and the imperative sentence "Go to... right now!" contribute to the fact that the consumers are inspired to go to the shops and consume.

Sales reps is the most suitable identity to serve the function of informing and promoting as a marketer. Contents of such 
type of discourse are mostly around the attributes of the product. The speech acts of purchasing are connotative in introducing the product and updating the information of promotion activity, etc. The tone of the language is extremely appealing.

\subsubsection{Adviser}

The pragmatic identity of adviser is defined as a man of wisdom who gives advice on how to live a happy life which is seemingly irrelevant to product, brand or service in question. Some marketing discourse on social media resort to this identity to create an objective stance.

Extract 7

"Follow your dreams." On \#InternationalWomensDay, Apple inspires girls to reach for their dreams.

This discourse of short length posted on Apple's public account on Twitter calls on girls to chase their dreams, which establishes an identity of an adviser in this imperative sentence. As an adviser, he doesn't speak a single word about any product of Apple, but an inspiring suggestion for girls on such a special day-International Women's Day out of good will.

Another Chinese marketing discourse shares the same practice.

Extract 8

\#媳妇套路深\# 跟媳妇商量吃什么? 去哪吃? 这是一道 深藏套路的题。答得好送分, 答不好送命! 看完视频, 让 你绝地重生, 如释重负, 逃过“生死劫”。学会这种套路, 让“送命题”轻松变为“送分题”。

Translated text: \#Wives'tricky trap\# “Where shall we go for dinner?" This is a very tricky question when a wife asks her husband. A wise answer may win you a glory while a stupid answer may cause you big troubles. Watch this Video and learn the tricks. You will definitely get relieved and turn this fatal question into a bonus.

In this Chinese example, the marketer plays the role of a knowledgeable and witty man who provides consumers with a solution to the tricky question, successfully avoiding the trap. Consumers are lured into watching this video in which eventually advertising purpose is achieved.

Acting as an adviser, enterprises personify themselves. A personal relationship is established with the public through giving advice based on ordinary people's life experience. This pragmatic identity turns the formal, organizational nature of an enterprise image into the informal, personalized nature, thus gain the reliability of customers.

\subsubsection{Expert}

The pragmatic identity of an expert is a person who is professional in a particular area of work or study and gives advice to people based on his expertise in his profession. Different from the 4 subjective identities introduced above, expert takes an objective perspective to assess the product based on his expertise. Thus, the discourse attaches great importance to the content which highlights the expert's professionalism.

Extract 9

This is iPhone 7. It makes all the things you do with your iPhone better, faster, and more powerful. Two new
choices-Black and Jet Black — hightlight its seamless design. A new camera captures shots you never could before. That's because its larger f1.8 capture, new sensor, and six-element lens enable brighter, more detailed photos and videos. And Optical Image Stabilization allows for a longer exposure, so you can even better images in low light. The Apple-designed Image Signal Processor analyzes every shot to automatically deliver the very best result. And the Quad- LED True Tone Flash illuminates brighter and farther.

In this example, the marketer constructs the identity of an expert who uses his professional knowledge to evaluate outstanding features and technologies applied in the smart phone. Numerous technical terms such as "Optical Image Stabilization" "Image Signal Processor", "Quad- LED True Tone Flash" are complicated and not necessarily familiar to consumers. The marketer adopts these terms in this discourse on purpose, constructing an expert identity which is seemingly more reliable to consumers.

Extract 10

前掌底部 $D S P+C A R B O N$ 材质前掌底部大面积使用 $D S P$ 轻质材料提升抓地性和耐久性底部足弓部位采用 $C A R B O N$ 轻料材质全程保护双脚

Translated text: The bottom of forepalm is made of DSP + CARBON. The bottom of forepalm is made of large area of light material of DSP to improve grip and durability. The bottom arch of foot is made of light material of CARBON to protect both feet.

In this example, the marketer evaluates the materials and functions of the shoes by employing jargons and abbreviations unknown to the consumers, which creates a professional image of an expert.

As an expert, sellers tend to use some jargons and terms or give some professional advice in their marketing discourses to enhance their credibility as an expert who is somewhat attractive to consumers.

\subsubsection{Official Introducer}

The pragmatic identity of official introducer is the product or service introducer on behalf of the authoritative sources who takes an objective stance. An official introducer is somewhat similar to a sales representative. But an official introducer's duty is to inform while a sales representative's duty is to persuade so that factual rather than affective expressions are employed in the marketing discourse to construct an official introducer identity. Here are two examples.

Extract 11

We believe that burger should only be flame-grilled, not cooked on a flattop. That's why we're introducing the new flame grill double quarter, pound cake. Rest in flames flattop coke burger. Introducing the new media cheesy double quarter pound cake, with over 1/2 pound of flame grilled beef homing at Burger King.

Different from a sales rep identity, an official introducer avoids the use of inductive rhetoric but neutral, plain and succinct discourse when introducing new products.

Extract 12 
\#华为 P20\#系列拥有高贵的宝石蓝、柔和的樱粉金、稳 重的亮黑色，更将 18 年流行色紫色融入机身，带来极具 时尚感的极光色, 由深至浅层层晕开, 充满无尽想象空间。

Translated text: HUAWEI P20 series have different colors for your choice, such as turquoise blue, cherry, pink, gold, black. Purple, as the most popular color in 2018, is evolved into the color of aurora for P20 series.

In the two examples, technical terms and jargon are adopted to introduce the products which constructs an expert identity for the marketer. Information conveyed in the marketing discourse may not be fully understood by the consumer but a reliable and professional image generated here wins consumers' confidence in the product.

\subsection{The Distribution and Features of Pragmatic Identities in Chinese and American Discourse on Social Media}

According to the statistics from Chinese mini-corpus of marketing discourse (each brand's 30 discourses, in total 150 discourses) from Chinese mainstream social media platforms in this study, as is shown in Table 3, the construction of 6 identities decreases progressively. Official introducer ranks the highest, accounting for $40 \%$. Sales representative ranks the second, $29 \%$, friend and expert are $15 \%$ and $10 \%$ respectively. Experiencer and adviser are at the bottom. The construction of subjective identity equals objective identity in number. The subjective identities are more diverse in category than objective identities.

Table 3. The Distribution of Pragmatic Identities in Chinese Discourse.

\begin{tabular}{llllll}
\hline Subjective Identity & & & & Objective Identity \\
\hline Experiencer & Sales Rep & Friend & Adviser & Expert & Official Introducer \\
\hline 4 & 47 & 24 & 9 & 17 & 62 \\
$2 \%$ & $29 \%$ & $15 \%$ & $5 \%$ & $10 \%$ & $40 \%$ \\
\hline
\end{tabular}

In comparison, based on the counting of American mini-corpus of marketing discourse (each brand's 30 discourse, in total 150 discourse), shown in Table 4, experiencer, sales representative and official introducer are top three identities in American discourse, equally distributed while the rest three amount to less than $20 \%$ in aggregation.

Table 4. The distribution of pragmatic identities in American discourse.

\begin{tabular}{llllll}
\hline Subjective Identity & & & \multicolumn{2}{l}{ Objective Identity } \\
\hline Experiencer & Sales Rep & Friend & Adviser & Expert & Official Introducer \\
\hline 34 & 44 & 12 & 12 & 8 & 44 \\
$22 \%$ & $28 \%$ & $7 \%$ & $7 \%$ & $5 \%$ & $28 \%$ \\
\hline
\end{tabular}

There are some similarities of the pragmatic identities between Chinese and American Marketing discourse on social media (see Table 5). The six pragmatic identities are used both in China and America. Official introducer and sales representative are the top two identities both in China and America. China and America have almost the same proportion of Sales representative identity. Adviser is not popular in both China and US. For rational identity category, both China and America adopt official introducer identity much more than expert identity. The emotional identities are widely constructed in marketing discourse on social media both in China and America.

Table 5. The comparison of pragmatic identity between Chinese and American discourse.

\begin{tabular}{llllll}
\hline \multirow{2}{*}{ Country } & Type & Emotional Identity & & & \multicolumn{2}{c}{ Rational Identity } \\
\cline { 2 - 6 } & Experiencer & Sales Rep & Friend & Adviser & Expert \\
\hline China & $2 \%$ & $29 \%$ & $15 \%$ & $5 \%$ & $10 \%$ \\
America & $22 \%$ & $28 \%$ & $7 \%$ & $7 \%$ & $5 \%$ \\
\hline
\end{tabular}

As for differences, America adopts the identity of experience, adviser more than China. China adopts expert and official introducer identity more than America. Emotional identity takes larger proportion than rational identity in America while they are equally distributed in China. But one exception is that friend identity is used more in China than in America. Experiencer identity appears in America ten times as many as in China. Official introducer in China is two times as many as in America. In American discourse, experience, sales representative and official introducer are top three, equally distributed, the rest three amount to less than $20 \%$ in aggregation whereas in Chinese discourse, the use of all identities decreases progressively. Official introducer ranks the highest, accounting for $40 \%$. Sales representative ranks the second, $29 \%$, friend and expert are $15 \%$ and $10 \%$ respectively. Experience and adviser are at bottom. In China, official introducer outweighs sales representative by $1 / 3$ in number while both identities are used equally in America.

\section{Discussion}

\subsection{Similarities}

Increasingly, social media are largely considered by modern business as promising platforms to conduct the promotional activities as to effectively communicate with the targeted customers [16-19]. The more capable can organisations build and sustain emotional and social ties between their customers and with their brands, the more such organisations could have a close and solid relationship with those customers [20]. Based on the statistics, both Chinese and American marketing discourse on social media construct a larger variety of 
individual pragmatic identities rather than organizational pragmatic identities. Although six pragmatic identities-experiencer, sales representative, friend, adviser, expert and official introducer are unequally distributed, there is a general tendency for both Chinese and American enterprises to personify their organizational identities into individual identities. Emotionless and unanimated manufacturing machines become lively when they appear on stage as a human being by constructing an identity of an individual. Accordingly, the marketers' distance to consumers have been greatly reduced by such a one-on-one personal relationship.

Among these individual identities, identity of official introducer and sales representative are the top two identities both in Chinese and American marketing discourse on social media. Sales representative is used both in China and America. It is decided by the marketing feature. Social media has been largely realized as an effective mechanism that contributes to the firms' marketing aims and strategy, especially in the aspects related to customers' involvement, customer relationship management and communication [21, 22]. In essence, the fundamental goal is to "revealing communication on some promotional information so that it allows learning from one another's use and experiences, eventually benefitting all of the involved parties [23]". Such a promotional attribute of social media marketing predetermines that the sales rep identity should be much frequently constructed in the discourse. Both China and America adopt official introducer identity more than expert. For ordinary customers who are laymen for technology, the identity of expert is not welcomed because this identity is realized through the full employment of jargon and terms in the discourse which bore them severely.

Adviser identity is not regularly constructed in both Chinese and American discourse. This may attribute to the limited length of a discourse usually allowed to post on social media. The identity of adviser is established through the communication of information that is little related to the product but other information useful to reader in a general sense, mostly tips or instructions on how to live a better life. The purpose of setting up an adviser identity in marketing discourse is to extend care to customers with sincerity. But if an enterprise overperforms the identity of an adviser, the dissemination of marketing information is insufficient. Therefore, the adviser identity takes the least proportion both in Chinese and American discourse.

\subsection{Differences}

One prominent feature concerning the differences of pragmatic identity is that American marketing discourse on social media adopts the identity of experiencer, adviser more than Chinese counterpart. The number of experiencer identity appearing in American discourse is ten times as many as in Chinese counterpart. This feature may attribute to the different cultural perceptions about the relationship between individual and group, which is depicted by individualism/collectivism, one of the most examined cultural dimensions proposed by Hofstede [24]. Individualism/collectivism cultural dimension refers to the degree to which individuals are integrated into groups. America is an individualistic society where personality, individual beliefs are highly valued. Therefore, in American society, the identity of experiencer or adviser as an individual is legitimate to deliver personal views and beliefs towards a product meanwhile maintains credibility for self-assertiveness is highly valued in American social culture. Differently, China is a collectivistic society that stresses an individual's belongingness to a group. The collectivistic "We" identity carries a lot more weight than the individualistic "I" identity in the Chinese context [25]. In collectivistic China, trust is fostered more on structural relations between people than on personality traits. The experiencer or adviser identity in Chinese discourse is not as effective as in American discourse.

Second feature is that Chinese discourse adopts expert and official introducer identity more than American discourse. The number of official introducer identity in Chinese discourse is two times as many as in American discourse. As for the internal ratio, within Chinese discourse, official introducers outnumber sales representative by $1 / 3$ while within American discourse, both identities are used equally in number. Such a phenomenon reflects the cultural divide concerning power distance, which is another cultural value dimension proposed by Hofstede [26]. It classifies cultures on a continuum of high and low-power distance to define the extent to which the less powerful person in society accepts inequality in power and considers it as normal. China is a high power distance culture compared with America, which means it accepts power as part of society. People in high-power distance culture believe that power and authority are facts of life. Thus the instructive information from the authority is more likely to convince Chinese customers who value authority more than American customers, while personal feelings from both sellers and consumers are more intelligible to American consumers. Chinese consumers tend to rely on the official resource for information. It is considered more reliable.

The third feature is that American discourse adopts more subjective identities than objective identities whereas Chinese discourse evenly employs both subjective and objective identities. This result is against the presumption of this study that in Chinese marketing discourse on social media, subjective identity should take the largest proportions, since China is a relation-driven culture where personal relationship is more valued than the task itself [27]. The usual practice for Chinese businessmen to seek a business opportunity is to establishing personal relationship before talking about business. Therefore, in Chinese relation-driven culture, people's subjective observation derived from observer's feeling and emotion is more valued than objective measuring and rational thinking. However, the data suggest that subjective identity and objective identity take an equal ratio. There is just one exception that friend identity is used more in Chinese discourse than in American discourse. Apparently, Chinese relation-driven culture is mainly reflected in the employment of one type of subjective identity-friend. Social 
media followers are more likely to believe content produced from someone in their social network. These blogs thus assume more credibility because they are "endorsed" by people's contacts. Thus marketers utilize social media platform optimally for producing product information from a contact source which is assumed to be more reliable. Among family, lover, friend, colleague, being a friend is the most proper identity to start a personal relationship. Compared with Chinese discourse, American enterprises construct subjective pragmatic identity more frequently on social media. It might attribute to the nature of social media which disseminates information through personal interaction.

\subsection{Suggestions for Constructing Pragmatic Identities}

Enlightened by the observation of the features of pragmatic identity constructed in Chinese and American discourse respectively discussed above, this study provides some suggestions for enterprises on each side which aims to expand their market to each other's continent.

For American enterprises to expand their market in China, they should establish pragmatic identities of official introducer to fit into Chinese high power distance culture, featured with trustworthiness of authority. For Chinese enterprises to attract American consumers, we may emphasize personal feelings and immediate benefits from the perspective of customer experience. Therefore, we should increase the pragmatic identity of experiencer in marketing discourse on social media. Both sides are suggested to integrate six different pragmatic identities and use them tactically in discourse which will diversify the style of the discourse and make it more interesting and dynamic.

As for the linguistic representation of each pragmatic identity, the establishment of experiencer can be realized through the mentioning of different senses and the employment of adverb and adjective concerning different attributes of the product. The construction of identity of friend and adviser can both rely on the utilization of informal language style and humorous anecdotes to personify the enterprises. The friend identity can also be formulated by deliberate appropriation of intimate address form and adviser identity will be more solid if the content of the discourse has less relation to the product. The sales representative identity will be mostly generated when the contents of the discourse are about the attributes of the product, the speech acts of purchasing are connotative in introducing the product and updating the information of promotion activity and the tone of the language is positive and appealing. Expert and official introducer identity is created by the frequent employment of technical terms and jargon.

\section{Conclusion}

The pragmatic identity is an individual or organization's variable, negotiable and adaptable identity acquired through negotiation with communicators and contextual adaptation to meet the communicative goals. This study takes a cross-cultural perspective to investigate the features of pragmatic identities constructed in Chinese and American marketing discourse on social media. The findings suggest that Chinese and American enterprises both construct six different types of pragmatic identities (Experiencer, Sales Representative, Friend, Adviser, Expert and Official Introducer) in marketing discourse on social media. A larger variety of individual pragmatic identities rather than organizational pragmatic identities is employed in both American and Chinese marketing discourse on social media. Three cultural value dimensions (collectivism vs. individualism, high power distance vs. low power distance, relation-driven vs. task-driven) attributes to the different use of the pragmatic identities. Apart from the findings, this research has some limitations.

This study is based on 300 discourses of 5 types of products. The findings might not extensively apply to all products' marketing discourse on social media. Whether the diverse nature of products affects the construction of pragmatic identity has not been discussed in this study. Methodologically, this is a mixture of qualitative study and quantitative study. But quantitative analysis only relies on the counting of occurrences of all types of pragmatic identities.

\section{Acknowledgements}

This work is supported by the 2019 co-construction project of "A Contrastive Study of Marketing Discourse on Social Media between Guangzhou and Hong Kong” from The-13th-five-year-plan for philosophy and social sciences development fund of Guangzhou [Project No.: 2019GZGJ68].

\section{References}

[1] Chiu, C., Ip, C., \& Silverman, A. (2012). Understanding social media in China. McKinsey Quarterly, 2, 78-81.

[2] McCorkindale, T., Distaso. M. W. (2013). The Power of Social Media and Its Influence on Corporate Reputation. Malden: Blackwell Publishing Ltd.

[3] Men, L. J., Tsai, W. H. (2015). Infusing social media with humanity: corporate character, public engagement, and relational outcomes. Public Relations Review, 41 (3), 395-403.

[4] Seltzer, T., Mitrook, M. A. (2007). The dialogic potential of weblogs in relationship building. Public Relations Review, 33 (2), 227-229.

[5] Chen, X. R. (2013). Pragmatic identity: dynamic choice and discursive construction. Foreign Languages Research.(4): 27-32, 112 .

[6] Yuan, Z. M. (2013). Understanding identity discourse: a critical and sociolinguistic perspective. Journal of Multicultural Discourses, 8 (1): 79-85.

[7] Yuan, Z. M. (2014). On dynamic adaptability of pragmatic identity construction. Foreign Language Education (5): 30-34.

[8] Sun, L. (2015). The construction of pragmatic identities in Chinese master students' English thesis abstracts. Foreign Languages and their Teaching (5): 15-21. 
[9] Li, J. (2016). A study of pragmatic identity in acknowledgement section of doctoral dissertation. Foreign Languages Research (2): 33-38.

[10] Wu, Y. (2015). The pragmatic identities and discourse construction of English teachers in online courses. Journal of Guangxi Normal University: Philosophy and Social Sciences Edition (3): 165-171.

[11] Xu, M., Chen X. R. (2015). Identity construction and adaptability of college English teachers in classroom context. Foreign Language Education (3): 50-54.

[12] Chai, G. Y, Han H. (2017). Pragmatic identities in web-based governmental business publicity discourses. Foreign Language Education (1): 49-54.

[13] Li, J. (2016). The shift and construction of translator identities in translating English personal pronouns. Journal of PLA University of Foreign Languages (4): 134-142.

[14] Tracy, K. (2002). Everyday Talk: Building and Reflecting Identities. New York: Guilford Press.

[15] Birkinshaw, J, Brannen, M. Y., Tung, R. L. (2011). From a distance and generalizable to up close and grounded: reclaiming a place for qualitative methods in international business research. Journal of International Business Studies, $42(5), 573-581$.

[16] Popp, B, Woratschek, H. (2017). Consumers' relationships with brands and brand communities - the multifaceted roles of identification and satisfaction. Journal of Retailing \& Consumer Services, 35, 46-56.

[17] Harrigan, P., Evers, U., Miles, M., Daly, T. (2017). Customer engagement with tourism social media brands. Tour Management, 59, 597-609.

[18] Gao, Q., Feng, C. (2016). Branding with social media: user gratififications, usage patterns, and brand message content strategies. Computer Human Behavior, 63, 868-890.

[19] Kohli, C., Suri, R., Kapoor, A., (2015). Will social media kill branding? Bus Horizons. 58 (1), 35-44.

[20] Alalwan, A. A., Rana, N. P., Dwivedi, Y. K., \& Algharabat, R. (2017). Social media in marketing: A review and analysis of the existing literature. Telematics and Informatics, 34 (7), $1177-1190$.

[21] Filo, K., Lock, D., Karg, A., (2015). Sport and social media research: a review. Sport Management Review. 18 (2), 166181.

[22] Saxena, A., Khanna, U. (2013). Advertising on social network sites: a structural equation modelling approach. Vision 17 (1), $17-25$.

[23] Dwivedi, Y. K., Kapoor, K. K., Chen, H. (2015). Social media marketing and advertising. Market Review. 15 (3), 289-309.

[24] Hofstede, G. (1984). Cultural dimensions in management and planning. Asia Pacific Journal of Management, 1 (2), 81-99.

[25] Hofstede, G. (2011). Organising for cultural diversity. European Management Journal, 7 (4), 390-397.

[26] Hofstede, G. (2001). Culture's recent consequences: using dimension scores in theory and research. International Journal of Cross Cultural Management, 1 (1), 11-30.

[27] Hall, E. T. (1976) Beyond Culture. New York, NY: Doubleday. 